\title{
The Design and Implementation of an Intelligent Apparel Recommend Expert System
}

\author{
A. H. Dong, ${ }^{1,2}$ D. Shan, ${ }^{1}$ Z. Ruan, ${ }^{1}$ L. Y. Zhou, ${ }^{3}$ and F. Zuo ${ }^{1,2}$ \\ ${ }^{1}$ College of Information Science and Technology, Donghua University, Shanghai 201620, China \\ ${ }^{2}$ Engineering Research Center of Digitized Textile \& Fashion Technology, Ministry of Education, Shanghai 201620, China \\ ${ }^{3}$ College of Textile, Donghua University, Shanghai 201620, China
}

Correspondence should be addressed to A. H. Dong; dongaihua@dhu.edu.cn

Received 11 January 2013; Accepted 5 February 2013

Academic Editor: Yang Tang

Copyright (C) 2013 A. H. Dong et al. This is an open access article distributed under the Creative Commons Attribution License, which permits unrestricted use, distribution, and reproduction in any medium, provided the original work is properly cited.

\begin{abstract}
Now with the rapid development of information science and technology, intelligent apparel recommend has drawn wide attention in apparel retail industry. Intelligent management and effective recommend are two issues of crucial importance for the retail store to enhance its corporate influence and increase its economic benefits. This paper proposes an intelligent recommend system design scheme for apparel retail which is based on expert system. By comprehensive utilization of database management and expert system technology, the proposed system provides a solid solution in improving the customer shopping experience. This paper presents a kind of object-oriented blackboard structure, which is applied in the apparel recommend expert system and establishes expert rule on the basis of apparel characteristic elements. Through the establishment of the rule base, the system generates personal recommend list by positive rule reasoning mechanism engine. The proposed method thus gives dress collocation scheme for the customer through the human-machine interaction from the point of view of the apparel experts. This design scheme avails the customers to experience targeted service with intellectualization, and personalization and it has certain reference significance for promoting apparel retail intelligence development.
\end{abstract}

\section{Introduction}

Expert system is one of the most active and productive research in the artificial intelligence field now. Since Edward Feganbaum developed the first expert system, DENDRL, expert system has developed rapidly. It simulates the experts' thinking process of solving the problem, and is widely used in medical diagnosis, geological exploration, the petroleum chemical industry, and so forth. Also, it brings great economic and social benefits in these fields [1].

With the expanding of apparel consumer market and increasingly fierce competition, apparel intelligent recommend has drawn wide attention in apparel retail industry. Intelligent recommend is an issue of crucial importance for the retail store to enhance its corporate influence and increase its economic benefits. Over the last several decades, apparel recommended technology has made some achievements at home and abroad. Recommender system firstly appeared in
1997 [2]. It refers to an application technology for knowledge discovery in a specific database. Some scholars applied intelligent agent and collaborative filtering technology in recommender service $[3,4]$. Most of the recommendation systems are designed based on the analysis of product attributes, customer attributes, or customer behaviors. In 2003, Lam invented an apparatus for personalized apparel coordination. This invention facilitates a user to select, coordinate, appraise, and harmonize apparel without actually putting on the clothing [5]. However, the apparatus is unable to give any evaluations about the coordination. In 2004, Kobayashi proposed a color planning method for coordinating apparel colors [6]. However, this method was from the perspective of apparel color to make dress collocation and recommend for users. In 2009, Wong et al. proposed a fashion mix-andmatch expert system [7]. In their study, the expert system was developed to provide customers with professional and systematic mix-and-match recommendations automatically. 
This system could capture the knowledge and emulate the decisions of fashion designers on apparel coordination, and its knowledge base could store the literal form of information. This system thus generated effective mix-and-match recommendations for customers. Although expert system and apparel recommended technology matures, the case that intelligent recommend system applied in apparel retail is less.

In this study, intelligent recommend system design scheme for apparel retail based on expert system technology is proposed to provide professional and systematic expert recommendations. As is known to all, owing to custom influence, seasonal factor, and fashion trend, apparel industry updates and changes quickly. Improving service quality is therefore essential for enhancing the brand image so as to obtain more economic benefits for the apparel retail. Dress is different from other commodities. It is related to many factors, such as color, style, and collar type. In view of the particularity of apparel goods, this system first consults the customer information such as the body characteristics and color of skin conditions. It then automatically generates recommended clothes which is suitable for the customer. In other words, it can simulate the thinking process of apparel recommend experts and use expert rules to recommend clothes for customers in the perspective of professionals. It avails the customers to experience targeted service with intellectualization and personalization, and it has certain reference significance for promoting apparel retail intelligence development.

The rest of the paper is organized as follows: Section 2 formulates the structure of apparel intelligent recommend expert system. It also analyzes how to represent and acquire the expert system rules. Section 3 presents expert system working process and principle. At the same time, it elaborates the system structure of blackboard in details. Section 4 describes the system design and implementation with experimental data. Section 5 draws the conclusion and the states of the possible further research direction.

\section{Designing of Intelligent Apparel Recommend Expert System}

Among all artificial intelligence research fields, expert system has the most practical value, and recently its application technology becomes more mature. Expert system is a kind of computer programming system, which uses specialized knowledge and ratiocination to solve problem in some specific fields [8]. That is to say, abundant specialized knowledge about the costume collocation has already been stored in the expert system illustrated in this paper. For those customers who do not qualify with this specialized knowledge, the proposed apparel recommend expert system can generate the recommendations sheet according to their personal information and give explanations on these recommendations.

\subsection{Structure of Intelligent Apparel Recommend Expert System.} The expert system illustrated in this paper is based on the expert rules. It can help customers selecting the most suitable clothes among the abundant apparel according to personal condition and increase customers' satisfaction. The structure of apparel recommended expert system is shown in Figure 1. It contains human interface, inference machine, knowledge base, database, and explaining organization. The rule base and inference machine are the kernel of the system.

Among all these modules in Figure 1, human machine interface (HMI) module is to realize the interaction between the system and customers. Firstly, the customer's basic information is obtained from the customer via the HMI to generate the personal information elements (skin color preference, figure type, face type, etc.). On the other hand, the recommendation sheet is also provided to the customer via HMI. Inference machine is the "brain" of the system. Depth-first search mechanism is applied in the expert system [9]. It uses production rule (a kind of forward reasoning method) [10] to invoke the expert rule in the knowledge base, and finally generates the apparel recommendation sheet. Knowledge base module contains fact base and rule base. Fact base is designed to store the train data of clothes. Rule base is the main part of the knowledge base. The dynamic database stores the intermediate result of system ratiocination. The explaining organization gives reasons on the final recommendation according to the intermediate ratiocination. It makes the expert system more transparent, and further on, increases the customers' satisfaction. Figure 2 shows the flow of the system working.

2.2. Presentation of Rule. Generally, human knowledge expresses and spreads via words and language. However, in order to be understood and ratiocinated by computer, it has to be formalized into a model which computer can recognize. This system introduced a definition of production rule. Usually, knowledge definition of production rules expressed as follows [11]:

$$
\text { If } A \text { Then } B \text {. }
$$

Which means if $A$ set up, $B$ also, established. It is simplified to

$$
A \longrightarrow B
$$

2.3. Rules Acquisition. Apparel is a kind of peculiar commodity. From the perspective of costume design, each piece of apparel is composed of variety of characteristic elements. Whether each apparel characteristic element or the collocation between each factor matchs mainstream aesthetic is closely related to the physical characteristics of personal appearance, body conditions, or other factors. This paper combined with the research on expert advice on apparel merchandise put costume commodity into varieties of characteristic elements and characteristic elements of the decomposition factor. Table 1 shows the detailed apparel commodity characteristics elements, including color, style, collar type, pants type, skirt type, waist type, and sleeve type.

Taking the advice of dress collocation expert, the proposed system is designed from the following aspects: the collocation of skin color and apparel color, the collocation of stature and apparel style, the fitness of collar type to the 


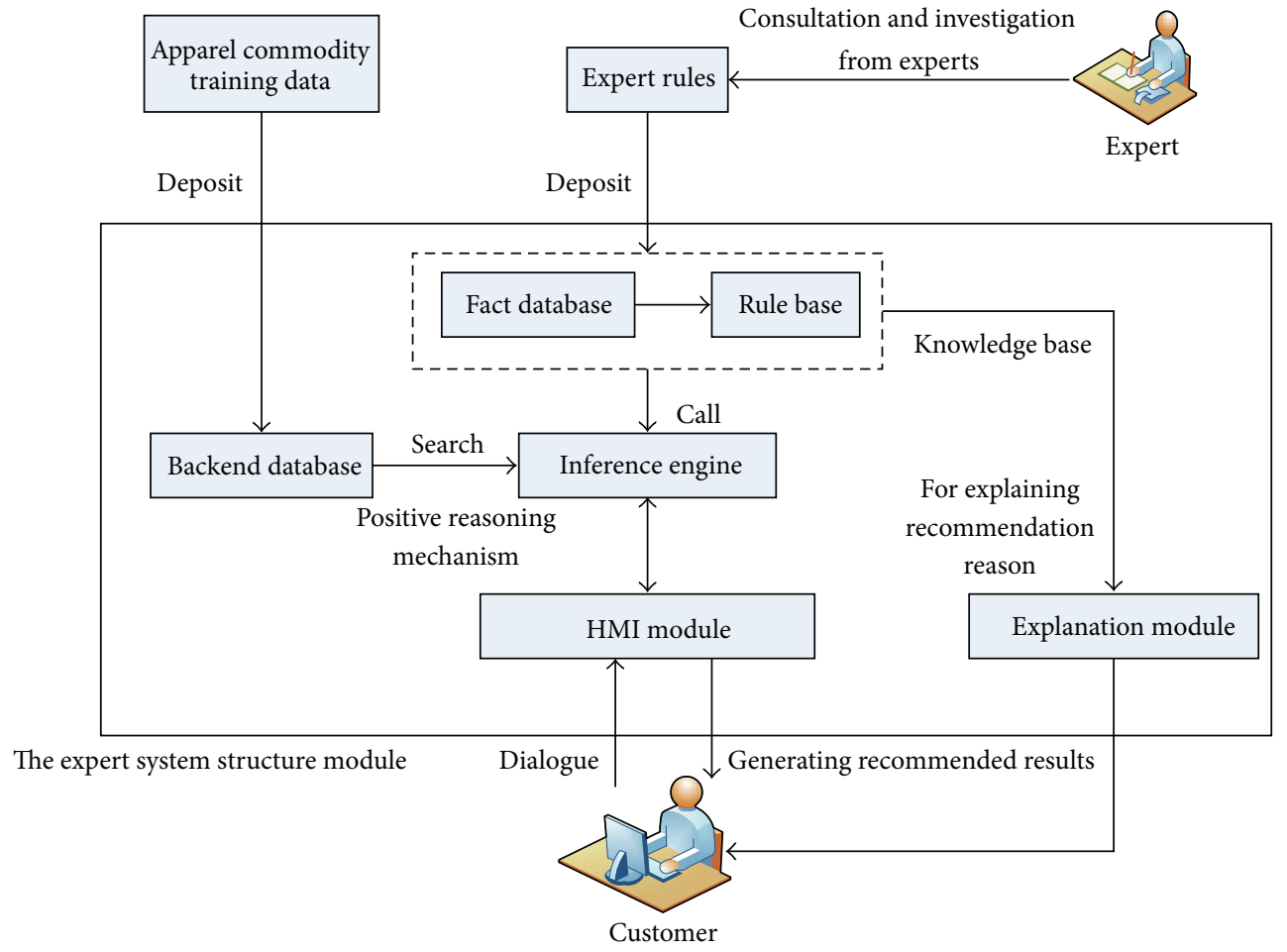

FIGURE 1: Structure of apparel intelligent recommend expert system.

TABLE 1: Apparel merchandise characteristic elements of the decomposition table.

\begin{tabular}{|c|c|}
\hline $\begin{array}{l}\text { Characteristic } \\
\text { elements }\end{array}$ & Name of characteristic elements of factoring \\
\hline Color & $\begin{array}{l}\text { Yellow, cream, orange, blue, shallow water, light } \\
\text { gold, gold, orange, red, brown, black, white, gray, } \\
\text { rose red, beige, green fruit, pink, blue, brown, pink }\end{array}$ \\
\hline Style & $\begin{array}{l}\text { Commuter, Korean, British, fresh, lady, sweet, } \\
\text { sexy, leisure }\end{array}$ \\
\hline Collar type & $\begin{array}{l}\text { V-neck, low round neck, deep U-neck collar, } \\
\text { round neck, POLO collar, stand-up collar, high } \\
\text { collar }\end{array}$ \\
\hline Pants type & Harem pants, leggings, slim pants, pencil pants \\
\hline Skirt type & $\begin{array}{l}\text { A-line skirt, pleated skirt bud skirt, pencil skirt, } \\
\text { mini skirt, pleated skirt }\end{array}$ \\
\hline Waist type & Waist, high waist, low waist \\
\hline Sleeve type & $\begin{array}{l}\text { Puff, conventional sleeves, dolman sleeves, raglan } \\
\text { sleeves }\end{array}$ \\
\hline
\end{tabular}

face, and the apparel style of different situations. Then expert rules of this system are generated by selecting eight data types as characteristic elements, such as apparel color, style, collar type, and so forth. And different expert rules constitute different knowledge sources (KS).

\section{Blackboard Structure of Intelligent Apparel Recommend Expert System}

3.1. Blackboard Structure. Blackboard structure [12] is applied to the proposed apparel intelligent recommend expert system. It contains three parts: knowledge sources, blackboard and controlling program.

Actually, blackboard structure is the global database which is used to store the original data, intermediate ratiocination process, and ratiocination results; it acts as the medium in the interaction and communication of different knowledge sources. The information on the blackboard structure is divided into many layers, and each layer represents the description of costume information in different detail levels [13]. High level apparel collation scheme evolves from low level ones, so their relationship can be expressed in a tree structure. Generally, only knowledge sources can modify, insert and delete information on the blackboard.

In the proposed experts system, knowledge sources are the set of rules that generate apparel recommended program from the same point of view. Each knowledge source can complete apparel experts recommend work from different point of view of customers. Knowledge sources include both premise and action. Knowledge sources are independent of each other that cannot be called directly and can only communicate through the blackboard.

Control mechanism is used to monitor the change of blackboard information, which can inspect the premise of each knowledge source continuously. Usually, once the premise of a knowledge source is established, this knowledge will be activated immediately, conduct the action of its part, and generate corresponding apparel recommendation scheme on the blackboard. And when change signal is sent by the information on blackboard, control mechanism can activate other knowledge sources, until the final recommendation scheme is generated [14]. The discipline is that when 


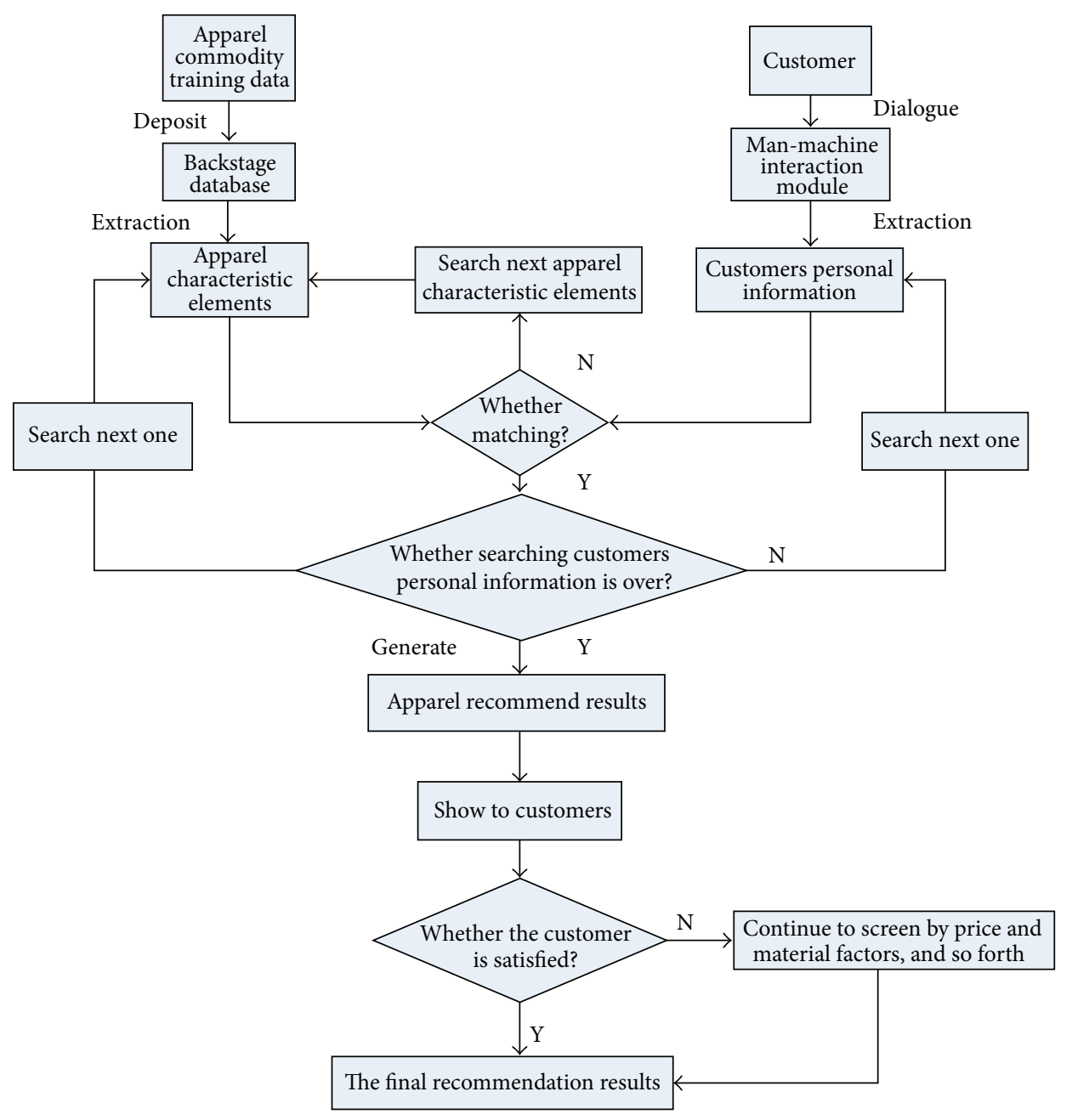

FIGURE 2: Flow chart of apparel intelligent recommend expert system.

the premises of multiple knowledge sources are coupled with the change state of blackboard information, the control mechanism can always choose the knowledge source which offers the best assistance to solve the problem to function first.

3.2. Task Tree of Blackboard Structure. The blackboard model is reasoning to random combinations to multiple knowledge sources multisub(task). The scheduler program between each subtask is a meta-level reasoning [15]. It make the use of the information generated from the blackboard to scheduling the reasoning of various knowledge sources; that is, the system is a meta-level knowledge and meta-level reasoning apparel recommended expert system. Based on the blackboard structure model, the problem that needs to be solved can be divided into a quest tree [16]. Therefore, a problem consists of multiple tasks, and each task can be solved by taking advantage of different knowledge sources.

As shown in Figure 3, the goal of apparel recommended expert system is to generate apparel recommended menu. This paper divides general task into six subtasks; each subtask took advantage of knowledge source to solve. The reasoning process is designed in positive reasoning mechanism engine
[17]. For example, through invoking the knowledge source of apparel color and skin color collation system can generates an apparel color scheme which is suitable for this customer. In another word, system recommends this customer in the aspect of apparel color and skin color collation, and generate the color scheme. Based on this recommendation, system invokes next knowledge source, makes a recommendation in the aspect of the collation of pants/skirt type and stature, and generate, corresponding scheme. And the like, system will do the similar job until transversing all tasks.

3.3. Analysis of the Blackboard Structure. The blackboard structure of apparel recommended expert system is shown in Figure 4. Blackboard structure is the workspace of the global database which is used to store all kinds of statuses produced in the ratiocination. It is divided into different layers. Data used and modified by different knowledge sources is on different layers [18]. Blackboard structure of this system is divided into 7 layers; each layer dispatches this layer's knowledge sources (KS) based on the upper layer, generates new recommendation scheme, and stores it to the next layer of the blackboard until all KS are dispatched. KS of this system 


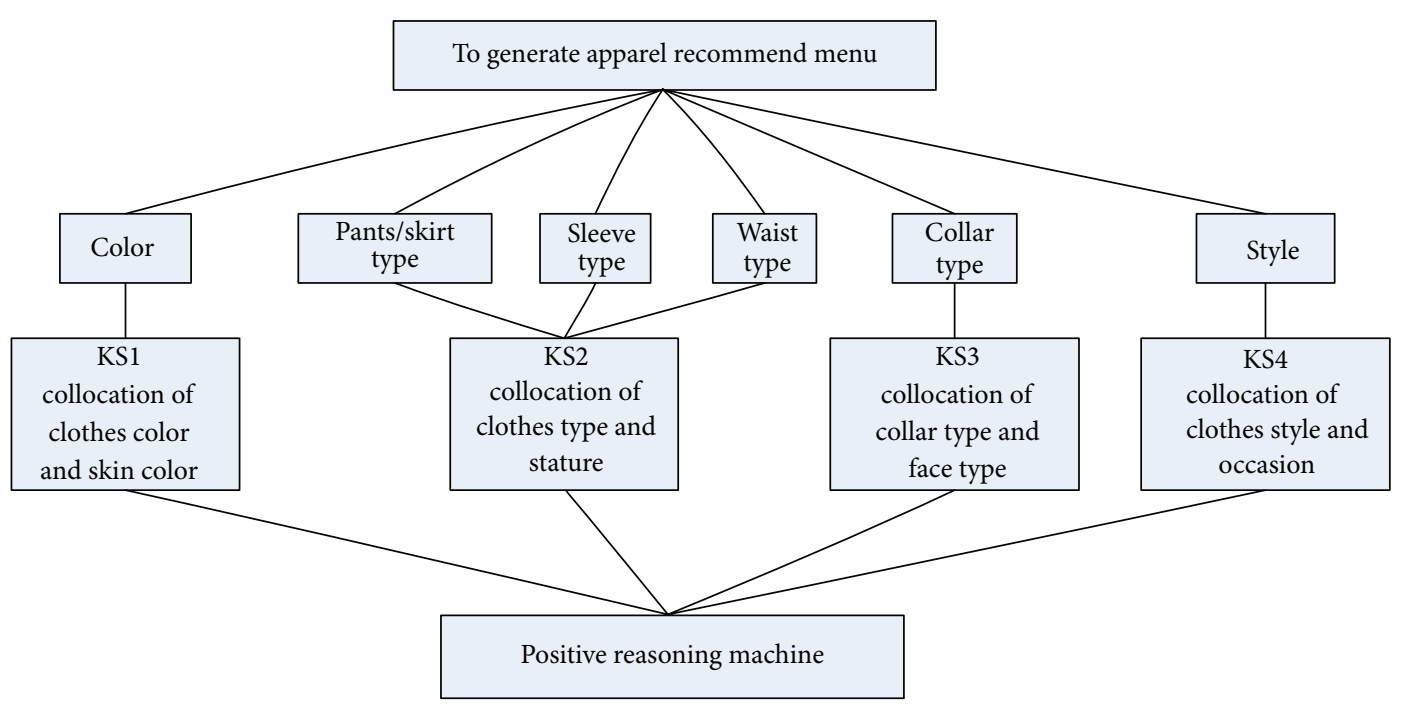

Figure 3: Task tree of blackboard structure.

can be divided into 4 kinds: KS1 is about the collocation of clothes color and skin color, KS2 is about the collocation of clothes type and stature, KS3 is about the collocation of collar type and face type, and KS4 is about the collocation of clothes style and situation. Command is used to activate KS when scheduling sequence dispatch $\mathrm{KS}$. The scheduling sequence is generated by the scheduling program, which is stored in the control database of this expert system.

After the interaction between customer and expert system, system will store the result of interaction on layer 1 of the blackboard automatically. Scheduling program will generate the scheduling sequence, activate $\mathrm{KS} 1$, and generate the recommendation scheme in the aspect of color. Then it will store the scheme on layer 2 of black board. System will dispatch KS2, continue the similar preclude on layer 2, and generate the recommendation scheme in the aspect of clothes type. And the like, till invoking KS4, system will form the final clothes recommendation sheet in all the 4 aspects: clothes color, style, type, and dress occasion.

Figure 5 illustrates the execution process of scheduling program from the bottom layer to the top layer of the black board. If the final recommendation sheet does not satisfy the customer successfully, the system could go back to the bottom layerand redo the whole procedure after more interactions with the customer, that makes the system have the feedback link of closed loop.

\section{Realization of Intelligent Apparel Recommend Expert System}

4.1. Development Environment. The common expert system developing languages include PROLOG and LISP, which are specially designed for the development of artificial intelligence system. The disadvantages of these languages include poor performance of visualization, difficulty in developing foreground, and bad controllability of reasoning process. In this paper, SQL Server 2005 is applied to store and process data while foreground program is developed in Visual C\#. C\# is objected-oriented language, and is the first choice for the development of foreground and various modules because of its excellent performance in the human-machine interaction and graphical display [19].

4.2. System Realization. The principle of the proposed apparel intelligent recommend expert system is that it changes recommend process into a state space search by using the known facts that constitute the initial state to generate of target state. The realization of the recommendation process therefore can be simplified to search route which is from the initial state to a target state in the whole state space by inference machine.

System testing data mainly sources from the opening apparel websites. In order to simulate the expert system of apparel shop, this system selects nearly 100 items of apparel information and stores them in the background database. And all these items form the training data set of the intelligent recommend expert system, including apparel name, apparel type, style, color, sleeve type, collar type, waist type, price, season, and material.

Apparel intelligent recommend expert system can call the rules in the rule base to match the fact in the fact repository according to the information which the customer submits via HMI. It then gets expert recommendation results. For example, a customer submits her information to this system which includes shallow yellowness of skin color, standard body shape, inverted triangle face, and dress occasions for home leisure. The expert system could generate apparel recommendation results after running program and show it to the customer via HMI, as shown in Figure 6. 


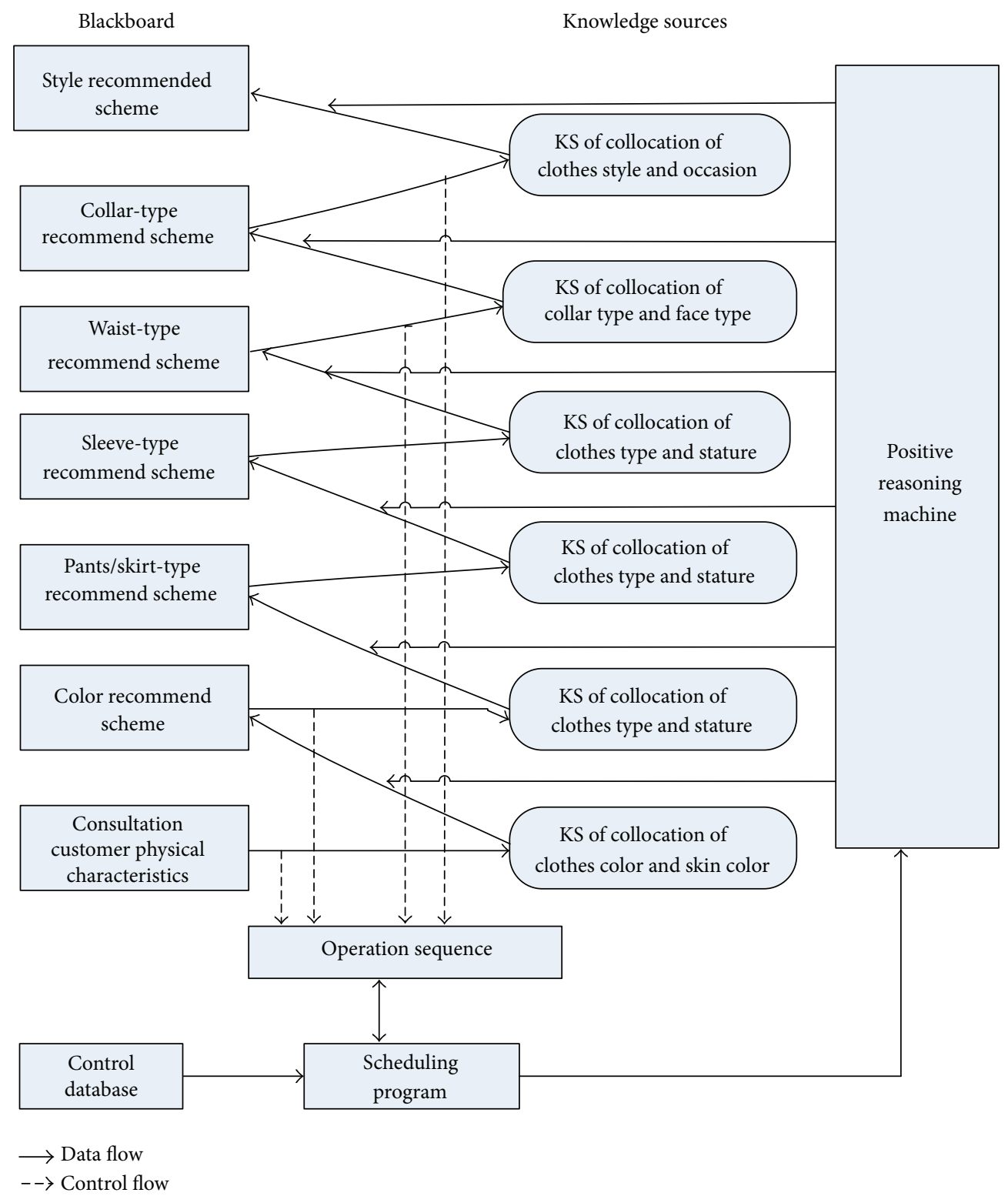

FIGURE 4: Blackboard structure of system.

If the customer is not satisfied with the recommendations of the system, the system allows the user to further screening according to the price, material, and so forth on the basic of recommendation results. At the same time, expert system can explain the reason of generating recommendation results. If the customer is still not satisfied with recommendation results, this system will automatically recommend popular apparel in sales season.

\section{Conclusions}

In this paper, an intelligent recommend expert system design scheme for apparel retail is proposed to provide professional and systematic apparel expert recommendations. The system designs a kind of object-oriented blackboard and establishes expert rule on the basis of apparel characteristic elements.
Through the establishment of rule base, the system generates personal recommend list by positive rule reasoning mechanism engine. The proposed method thus gives dress collocation scheme for the customer through the HMI from the point of view of the apparel experts. The experimental results using the test data demonstrate that the proposed system is effective. In short, the intelligent recommend method based on expert system could recommend the suitable apparel for the customer and improve the customer experience level. It avails the customers to experience targeted service with intellectualization and personalization, and it has certain reference significance for promoting apparel retail intelligence development.

As the popular trend of apparel varies year by year, related recommend knowledge from the experts may be changed as well. How to make the recommend expert systems generate 


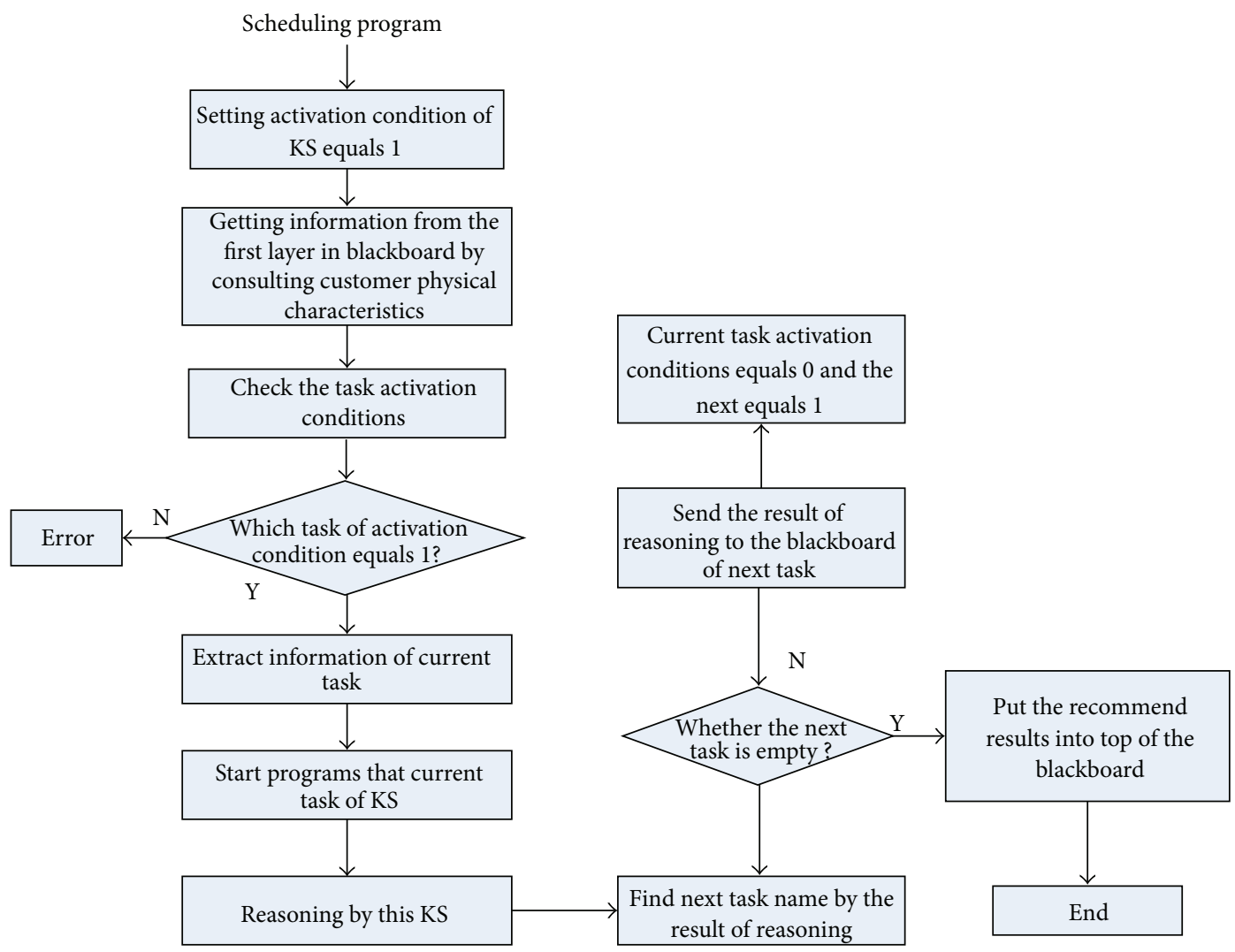

FIGURE 5: System scheduling program flow diagram.

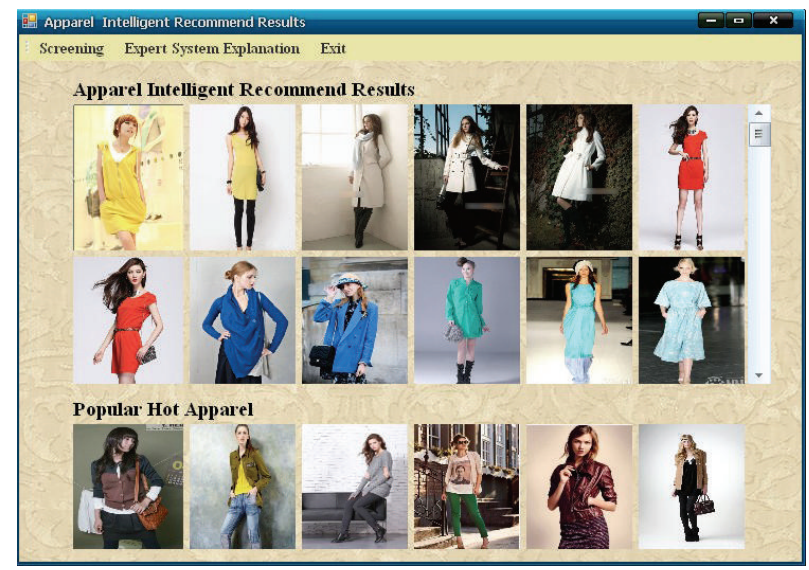

Figure 6: Effectiveness demonstration of system.

new rules automatically, namely, machine learning, is one of the possible directions of future research.

\section{Acknowledgments}

The financial support from the National Natural Science Foundation of China (12K10130) and from the Shanghai Natural Science Foundation (12S10155) is gratefully acknowledged.

\section{References}

[1] K. W. Chau and F. Albermani, "An expert system on design of liquid-retaining structures with blackboard architecture," Expert Systems, vol. 21, no. 4, pp. 183-191, 2004.

[2] P. Resnick and H. R. Varian, "Recommender systems," Communications of the ACM, vol. 40, no. 3, pp. 56-58, 1997.

[3] B. Sarwar, G. Karypis, J. Konstan, and J. Riedl, "Analysis of recommender algorithms for E-Commerence on electronic commerence," in Proceedings of the 2nd ACM Conference on Electronic Commerce, pp. 158-167, 2000. 
[4] B. Mobasher, H. Dai, T. Luo, Y. Sun, and J. Zhou, "Integrating web usage and content mining for more effective personalization," in Proceedings of the International Conference on ECommence and Web Technologies, pp. 165-176, 2000.

[5] P. A. F. Lam, "Personalized garment coordination apparatus," United States Patent, vol. 6, pp. 629-644, 2003.

[6] M. Kobayashi, "Studies on the color planning of clothingexistence of the "ideal skin color" and the effect of the clothing color," Journal of the Japan Research Association for Textile EndUses, vol. 45, no. 3, pp. 56-63, 2004.

[7] W. K. Wong, X. H. Zeng, W. M. R. Au, P. Y. Mok, and S. Y. S. Leung, "A fashion mix-and-match expert system for fashion retailers using fuzzy screening approach," Expert Systems with Applications, vol. 36, no. 2, pp. 1750-1764, 2009.

[8] R. Zhang, J. Lu, and G. Zhang, "A knowledge-based multi-role decision support system for ore blending cost optimization of blast furnaces," European Journal of Operational Research, vol. 215, no. 1, pp. 194-203, 2011.

[9] X. Y. Chi, H. J. Ma, Z. Zhao, and Y. H. Peng, "Research on hybrid expert system application to blanking technology," Journal of Materials Processing Technology, vol. 116, no. 2-3, pp. 95-100, 2001.

[10] J. Akoka and I. Comyn-Wattiau, "An expert system for software reverse engineering," in Procedings of the 4th World Congress of Expert Systems, Application of Advanced Information Technologies, vol. 1, pp. 209-217, 1998.

[11] M. Weiss and F. Stetter, "Hierarchical blackboard architecture for distributed AI systems," in Proceedings of the 4th International Conference on Software Engineering and Knowledge Engineering, pp. 349-355, June 1992.

[12] C. Reidsema and E. Szczerbicki, "A blackboard database model of the design planning process in concurrent engineering," Cybernetics and Systems, vol. 32, no. 7, pp. 755-774, 2001.

[13] Y. Tang, Z. Wang, H. Gao, S. Swift, and J. Kurths, "A constrained evolutionary computation method for detecting controlling regions of cortical networks," IEEE Transactions on Computational Biology and Bioinformatics, vol. 9, pp. 1569-1581, 2012.

[14] Y. Tang, H. Gao, J. Kurths, and J. Fang, "Evolutionary pinning control and its application in UAV coordination," IEEE Transactions on Industrial Informatics, vol. 8, pp. 828-838, 2012.

[15] Y. Tang, H. Gao, W. Zou, and J. Kurths, "Identifying controlling nodes in neuronal networks in different scales," PLOS ONE, vol. 7, no. 7, Article ID e41375, 2012.

[16] K. Eldrandaly and S. Naguib, "A knowledge-based system for GIS software selection," International Arab Journal of Information Technology. In press.

[17] G. Brzykcy, J. Martinek, A. Meissner, and P. Skrzypczyński, "Control aspects of the blackboard agent architecture for a mobile robot," Control and Cybernetics, vol. 32, no. 4, pp. 851866, 2003.

[18] J. G. Harvey and D. D. Harris, "Enhancing the blackboard concept to produce a flexible, extensible knowledge-based design tool," Knowledge-Based Systems, vol. 9, no. 4, pp. 233243, 1996.

[19] J. H. Liu, "The design of expert system and its realization based on C\#," Information and Technology, no. 4, pp. 150-153, 2006. 


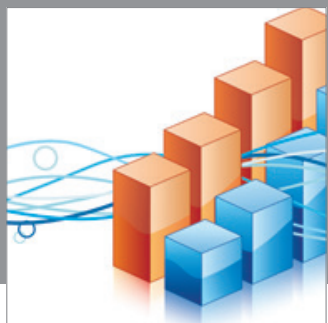

Advances in

Operations Research

mansans

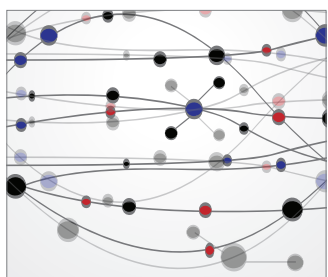

The Scientific World Journal
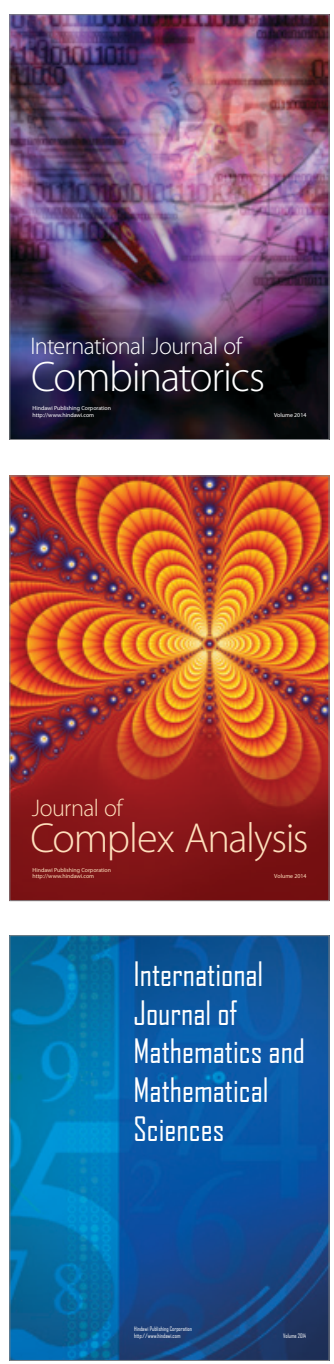
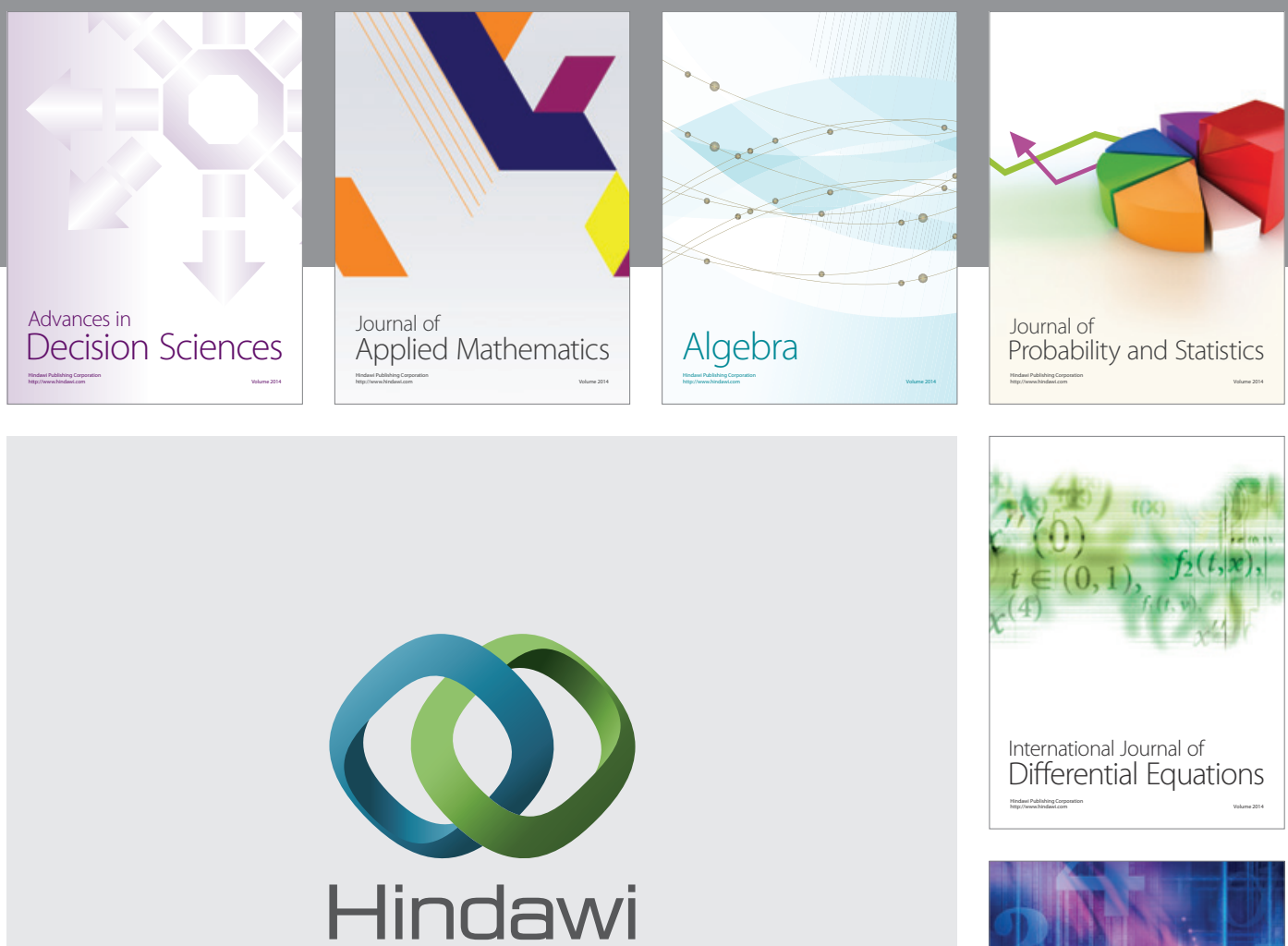

Submit your manuscripts at http://www.hindawi.com
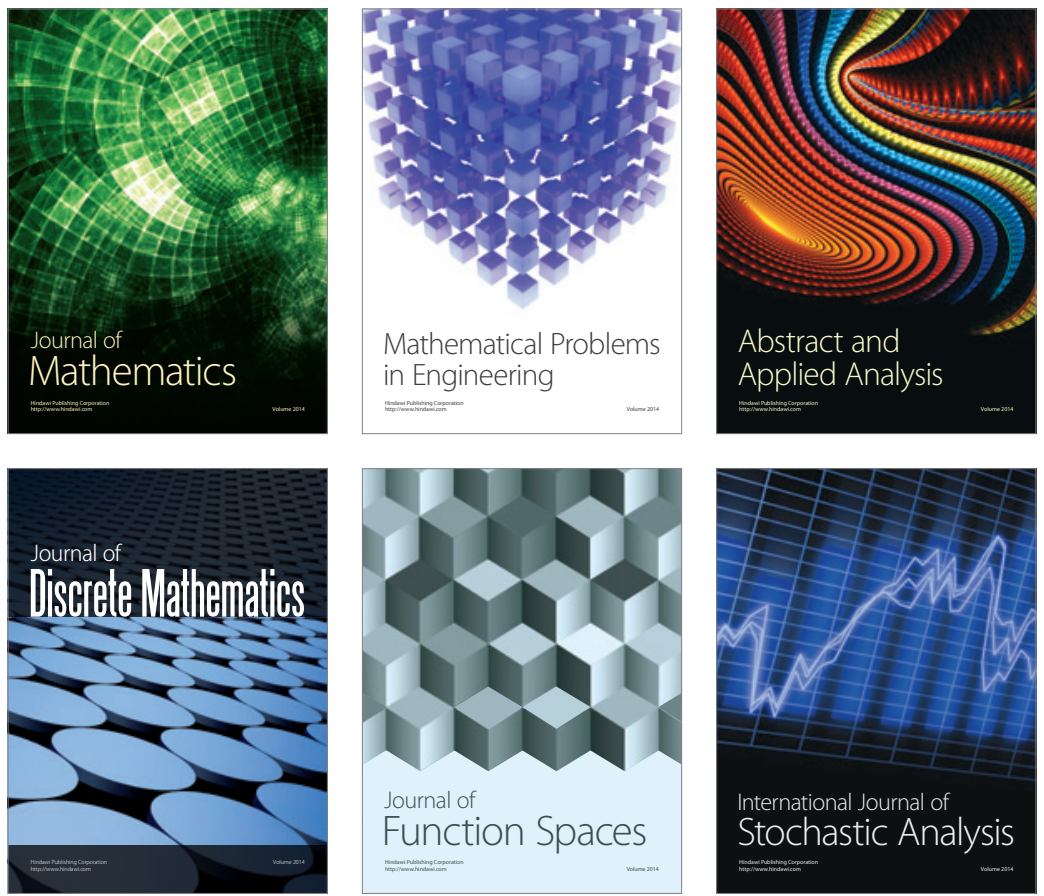

Journal of

Function Spaces

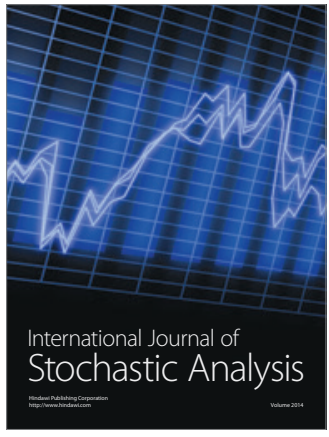

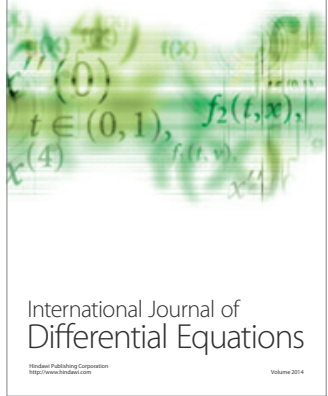
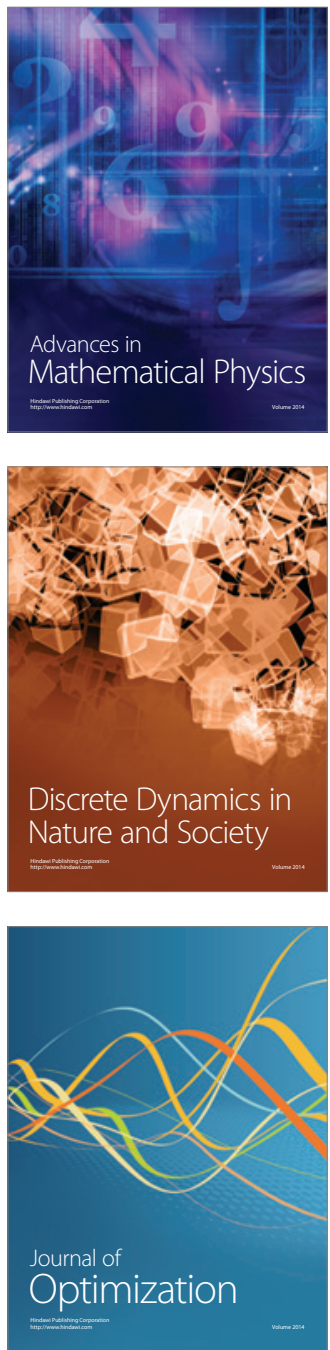